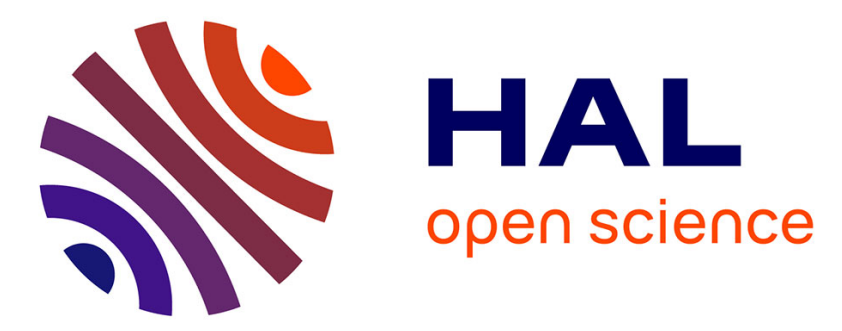

\title{
Comparison of ZrB2-SiC, HfB2-SiC and HfB2-SiC-Y2O3 oxidation mechanisms in air using LIF of BO2 $(\mathrm{g})$
}

\author{
V. Guérineau, Gautier Vilmart, Nelly Dorval, Aurélie Julian-Jankowiak
}

\section{To cite this version:}

V. Guérineau, Gautier Vilmart, Nelly Dorval, Aurélie Julian-Jankowiak. Comparison of ZrB2-SiC, HfB2-SiC and HfB2-SiC-Y2O3 oxidation mechanisms in air using LIF of BO2(g). Corrosion Science, 2019, pp.1-8. 10.1016/j.corsci.2019.108278 . hal-02382594

\section{HAL Id: hal-02382594 \\ https://hal.science/hal-02382594}

Submitted on 27 Nov 2019

HAL is a multi-disciplinary open access archive for the deposit and dissemination of scientific research documents, whether they are published or not. The documents may come from teaching and research institutions in France or abroad, or from public or private research centers.
L'archive ouverte pluridisciplinaire HAL, est destinée au dépôt et à la diffusion de documents scientifiques de niveau recherche, publiés ou non, émanant des établissements d'enseignement et de recherche français ou étrangers, des laboratoires publics ou privés. 


\title{
Comparison of $\mathrm{ZrB}_{2}-\mathrm{SiC}, \mathrm{HfB}_{2}-\mathrm{SiC}$ and $\mathrm{HfB}_{2}-\mathrm{SiC}-\mathrm{Y}_{2} \mathrm{O}_{3}$ oxidation mechanisms in air using LIF of $\mathrm{BO}_{2}(\mathrm{~g})$
}

\author{
V. Guérineau ${ }^{1}$, G. Vilmart ${ }^{2}$, N. Dorval ${ }^{2}$ andA. Julian-Jankowiak ${ }^{1, *}$ \\ ${ }^{a}$ DMAS, ONERA, Université Paris-Saclay, F-92322 Châtillon, France \\ ${ }^{\mathrm{b}}$ DPHY, ONERA, Université Paris-Saclay, F-91123 Palaiseau, France
}

*Corresponding author: aurelie.jankowiak@onera.fr

vincent1guerineau@gmail.com, aurelie.jankowiak@onera.fr, nelly.dorval@onera.fr, gautier.vilmart@onera.fr

\section{Declaration of interest: none}

\begin{abstract}
:
The oxidation behaviour of $\mathrm{ZrB}_{2}-\mathrm{SiC}, \mathrm{HfB}_{2}-\mathrm{SiC}$ and $\mathrm{HfB}_{2}-\mathrm{SiC}-\mathrm{Y}_{2} \mathrm{O}_{3}$ is studied using the real-time Laser-Induced Fluorescence (LIF) detection of $\mathrm{BO}_{2}(\mathrm{~g})$ evaporated from samples heated up to $1873 \mathrm{~K}$ in dry air. For each composition, the relevant steps of oxidation (silica formation, volatilization, etc.) can be precisely determined. Moreover, the influence of composition on the oxidation behaviour, and more precisely on the $\mathrm{B}_{2} \mathrm{O}_{3} / \mathrm{SiO}_{2}$ ratio in the glassy phase, can be understood and described by monitoring the LIF signal from the $\mathrm{BO}_{2}(\mathrm{~g})$ radical. Thus, this technique has confirmed the potential of the $\mathrm{HfB}_{2}-\mathrm{SiC}-\mathrm{Y}_{2} \mathrm{O}_{3}$ composition as a Ultra High Temperature Ceramic (UHTC) material.
\end{abstract}

KEYWORDS: (A) ceramic; (C) high temperature corrosion; (C) oxidation; (B) spectroscopy; (B) Laser Induced Fluorescence 


\section{Introduction}

Ultra-High Temperature Ceramics (UHTC) are extensively investigated as materials for applications in very high temperatures $(>2073 \mathrm{~K})$ and oxidising or corrosive atmospheres. Among this material family, UHTC borides, such as $\mathrm{ZrB}_{2}$ and $\mathrm{HfB}_{2}$-based ceramics, are particularly interesting since the melting points of these materials are high, and the mechanical, thermal and chemical properties are excellent. Hence, they might be ideal candidates for developing thermal protection systems on hypersonic aerospace vehicles or atmospheric re-entry vehicles which require a good oxidation resistance under severe conditions.

Thus, studying and understanding the oxidation resistance of such materials is essential. The influence of the $\mathrm{SiC}$ addition or of other additives (e.g. $\mathrm{TaSi}_{2}, \mathrm{MoSi}_{2}$ ) has been largely studied ${ }^{1-5}$ so that, the oxidation behaviour of $\mathrm{ZrB}_{2}-\mathrm{SiC}$ and $\mathrm{HfB}_{2}-\mathrm{SiC}$ is relatively well known up to $2073 \mathrm{~K}$ in air ${ }^{6-12}$. A few studies have also been carried out at higher temperatures and under other atmospheres than air ${ }^{13-19}$, for instance in the presence of humidity or in an oxyacetylene flame.

Although the key role of the borosilicate layer ${ }^{1,20,21}$ and finally of the $\mathrm{ZrO}_{2}$ or $\mathrm{HfO}_{2}$ layer 13,18,22 has been demonstrated, a very few studies attempted the in situ investigation of its behaviour during an oxidation test. The thermogravimetric analysis (TGA) ${ }^{20}$ and the optical emission spectroscopy have been used elsewhere ${ }^{23,24}$. However, TGA only gives the sum of the weight gains and weight losses and only provides insights about the chemical evolution of the borosilicate layer. Investigations by emission spectroscopy imply that the chemical species are formed in sufficient quantity in an excited state to be detected through the radiative deactivation process, thus making this technique slightly sensitive. Previously, we have proposed the Laser-Induced Fluorescence (LIF) technique to detect gaseous $\mathrm{BO}_{2}(\mathrm{~g})$ radicals above the sample during oxidation of $\mathrm{ZrB}_{2}$ and $\mathrm{ZrB}_{2}-\mathrm{SiC}$ samples ${ }^{25}$. These radical 
species come from the volatilization of $\mathrm{B}_{2} \mathrm{O}_{3}$ from the glassy layers. The LIF technique enables the detection of $\mathrm{BO}_{2}$ radicals with much better sensitivity, spatial and temporal resolutions than emission spectroscopy. Laser excitation of $\mathrm{BO}_{2}$ is performed at $547.3 \mathrm{~nm}$ to promote the $A^{2} \Pi_{u}(0,0,0)-X^{2} \Pi_{g}(0,0,0)$ vibronic band originating from the ground state. The subsequent fluorescence is detected via the $A^{2} \Pi_{u}(0,0,0) \rightarrow X^{2} \Pi_{g}(1,0,0)$ red-shifted band at $580 \mathrm{~nm}^{25}$. In contrast to the TGA analysis, oxidation detection is delayed since $\mathrm{B}_{2} \mathrm{O}_{3}$ has to be formed prior to the detection of $\mathrm{BO}_{2}(\mathrm{~g})^{23}$. However, the further evolutions of the glassy layer are markedly detected using the LIF technique such as the onset of the oxidation of SiC or the intense volatilization of the glassy layer at temperatures higher than $1500 \mathrm{~K}$.

This paper presents a comparison of the oxidation mechanisms of $\mathrm{ZrB}_{2}-\mathrm{SiC}, \mathrm{HfB}_{2}-\mathrm{SiC}$ and $\mathrm{HfB}_{2}-\mathrm{SiC}-\mathrm{Y}_{2} \mathrm{O}_{3}$ by using the same real-time LIF detection strategy of evaporated $\mathrm{BO}_{2}$ above the $\mathrm{ZrB}_{2}, \mathrm{ZrB}_{2}-\mathrm{SiC}$ samples heated in air, a technique which has been applied for the first time in our previous article ${ }^{25}$. The influence of the composition on the oxidation behaviour is described in details and the potential of the LIF technique for thermal oxidation detection is confirmed here in the case of the $\mathrm{HfB}_{2}$-based ceramics.

\section{Materials and apparatus}

\subsection{Materials}

Three UHTC compositions are studied: $\mathrm{ZrB}_{2}+20$ vol\% SiC, labelled ZS, $\mathrm{HfB}_{2}+20$ vol\% SiC, labelled HS and $\mathrm{HfB}_{2}+20$ vol\% $\mathrm{SiC}+3 \mathrm{vol} \% \mathrm{Y}_{2} \mathrm{O}_{3}$, labelled HSY. Properties of the starting powders are listed in Table 1.

\begin{tabular}{|lllll}
\hline Powder & Provider & Grade & $\mathrm{d}_{50}(\mu \mathrm{m})$ & Purity \\
\hline $\mathrm{ZrB}_{2}$ & H.C. Starck & $\mathrm{A}$ & $\mathbf{2 . 8}$ & $>\mathbf{9 7 . 8}$ \\
\hline $\mathrm{HfB}_{2}$ & H.C. Starck & $\mathrm{A}$ & $\mathbf{7 . 6}$ & $>97$ \\
\hline $\mathrm{SiC}$ & H.C. Starck & BF12 & $\mathbf{0 . 6}$ & $>98.5$ \\
\hline $\mathrm{Y}_{2} \mathrm{O}_{3}$ & Ampere Industrie & - & $<5$ & $\mathbf{9 9 . 9 9}$ \\
\hline
\end{tabular}

Table 1: Grade, purity and particle size of starting powders. 
After weighing, the powders are attrition-milled in cyclohexane using zirconia media (for ZS) or WC media (for HS and HSY), dried and sieved $(50 \mu \mathrm{m})$. Fully dense samples (20 to $40 \mathrm{~mm}$ in diameter) are obtained using Spark Plasma Sintering (SPS, FCT HD25) in the MATEIS laboratory (Lyon, France). More details concerning manufacturing have already been reported elsewhere ${ }^{13}$. The bulk density and open porosity of these materials are measured by the Archimedes' method. Then, the densification level is calculated as the ratio of the apparent density to the theoretical density of the powder mixture.

Sintering conditions and densification levels of the samples are reported in Table 2.

\begin{tabular}{|lllrll|} 
Composition & $\begin{array}{l}\text { Sintering } \\
\text { process }\end{array}$ & $\begin{array}{l}\text { Applied } \\
\text { pressure }\end{array}$ & $\begin{array}{c}\text { Thermal } \\
\text { treatment }\end{array}$ & $\begin{array}{l}\text { Open } \\
\text { porosity }\end{array}$ & $\begin{array}{l}\text { Densification } \\
\text { rate } \rho / \rho_{\text {th }}\end{array}$ \\
\hline $\mathrm{ZrB}_{2}+20 \mathrm{vol} \% \mathrm{SiC}$ & $\mathrm{SPS}$ & $28 \mathrm{MPa}$ & $2323 \mathrm{~K}, 2 \mathrm{~min}$ & $0.1 \%$ & $>99 \%$ \\
\hline $\mathrm{HfB}_{2}+20 \mathrm{vol} \% \mathrm{SiC}$ & $\mathrm{SPS}$ & $16 \mathrm{MPa}$ & $2223 \mathrm{~K}, 5 \mathrm{~min}$ & $1.8 \%$ & $97 \%$ \\
\hline $\begin{array}{l}\mathrm{HfB}_{2}+20 \mathrm{vol} \% \mathrm{SiC}+ \\
3 \mathrm{vol} \% \mathrm{Y}_{2} \mathrm{O}_{3}\end{array}$ & $\mathrm{SPS}$ & $7 \mathrm{MPa}$ & $2153 \mathrm{~K}, 5 \mathrm{~min}$ & $0.1 \%$ & $98.5 \%$ \\
\hline
\end{tabular}

Table 2: Sintering conditions and open porosity of the studied UHTC materials.

\subsection{LIF experiment}

During the thermal oxidation runs in air of the samples heated with a continuous wave $2 \mathrm{~kW} \mathrm{CO} 2$ laser, $\mathrm{BO}_{2}(\mathrm{~g})$ is detected in the evaporation plume by monitoring its fluorescence signal at $580 \mathrm{~nm}$ induced by laser excitation tuned to $547.3 \mathrm{~nm}$ as mentioned above ${ }^{26}$. A very detailed description of the set-up, the method and the experimental protocol were reported in our previous study ${ }^{25}$.

The dedicated chamber is equipped with optical windows for laser-based measurements. The $\mathrm{CO}_{2}$ laser irradiates the target at normal incidence angle from the top of the chamber (figure $1 \mathrm{a}$ ). The laser beam is focused on the target in order to irradiate the whole surface. The sample is mounted on an alumina holder in the chamber centre. The support can be translated upwards in order to adjust the height of the sample surface with respect to the probe laser beam axis. Surface temperature is measured with a bichromatic pyrometer in the 1273-2773 K range (Modline 6R-2565, Ircon). Synthetic air (Alphagaz 1) is 
injected in the chamber by means of a mass flow regulator, and is evacuated via a pumping system to maintain the pressure constant during the oxidation run.

The probe laser source is a tunable dye laser (Quantel, TDL50) pumped by a pulsed Nd:YAG laser (Quantel, YG781, $10 \mathrm{~Hz}$ repletion rate). The pulse duration is $6 \mathrm{~ns}$ and the linewidth is $0.07 \mathrm{~cm}^{-1}$. The output energy is $15 \mathrm{~mJ} /$ pulse and is attenuated to $1 \mathrm{~mJ}$ using neutral density filters. The probe laser beam is crossing the chamber horizontally through anti-reflection coated windows in the visible range. The beam is focused with a spherical lens ( $\mathrm{f}=600 \mathrm{~mm}$ ) to obtain a $1 \mathrm{~mm}$ laser spot at the sample location in the chamber. During a thermal oxidation run, the laser energy is recorded at the chamber exit by a photodetector (PD10, Ophir) in order to monitor the beam attenuation through the evaporation plume (absorption pathway in figure $1 \mathrm{~b}$ )

Fluorescence light is collected at right angle from the probe laser beam axis (fluorescence pathway in figure $1 \mathrm{~b}$ ) by a $100 \mathrm{~mm}$ focal-length lens coupled to an optical fibre ( $1 \mathrm{~mm}$ in diameter). The fluorescence is imaged with a magnification of 1 onto a monochromator (Jobin-Yvon, H-20) equipped with a $1 \mathrm{~mm}$ wide exit slit (4 $\mathrm{nm}$ bandpass centred at $580 \mathrm{~nm}$ ). The signal is then detected, amplified, time-integrated (34 ns temporal gate) and averaged (over 10 laser shots) by means of a photomultiplier tube (Photonis, XP2017B) and a Boxcar system (SRS, SR250) ${ }^{25}$. A Labview ${ }^{\circledR}$ interface is used to acquire integrated fluorescence signals via an acquisition PCI card (1.25 MHz, 16 bit) at $10 \mathrm{~Hz}$.

\subsection{Experimental protocol}

Once the sample is positioned on the holder, the chamber is evacuated prior to synthetic air injection with a $1.3 \mathrm{l} / \mathrm{min}$ flow rate. The pressure is regulated to $0.1 \mathrm{MPa}$, then the heating of the sample and the recording of both the LIF signal and the laser transmission can start. The $\mathrm{CO}_{2}$-laser power is monitored manually, thus allowing to hold temperature steady to perform timely several adjustments and to ensure that the LIF signal is properly monitored ${ }^{25}$. 
The nature and the thickness of each oxidised layer were identified through ex situ examinations in the Scanning Electron Microscope (SEM, DSM 962) and by Energy Dispersive Spectroscopy (EDS) of both the surface and the polished cross-sections of the oxidised materials.

In addition, TGA experiments (SETSYS Evolution 16/18, SETARAM) are carried out to measure the mass variations during oxidation of each composition. Samples $\left(2 \times 2 \times 4 \mathrm{~mm}^{3}\right.$ in size), are slowly heated $(2 \mathrm{~K} / \mathrm{min}$ ) from room temperature to $1823 \mathrm{~K}$ under a $50 \mathrm{ml} / \mathrm{min}$ air flow.

\section{Results}

The variation of amplitude of LIF and laser transmission signals as a function of time for ZS, HS and HSY samples is shown in figure 2. As for ZS samples ${ }^{25}$, four key steps can be identified for HS and HSY samples and are numbered from (1) to (4) in figure 2 but with noticeable differences in the amplitude of signal or in the temperature range associated with each step, as compared in Table 3.

Step (1) corresponds to the appearance of the LIF signal indicating that a detectable quantity of $\mathrm{BO}_{2}(\mathrm{~g})$ has been formed. This gaseous species comes from the volatilization of the $\mathrm{B}_{2} \mathrm{O}_{3}(\mathrm{l})$ glassy layer formed at the surface of the sample ( Reactions 1 and 2).

$$
\begin{aligned}
& \mathrm{MeB}_{2}+5 / 2 \mathrm{O}_{2} \rightarrow \mathrm{MeO}_{2}(\mathrm{~s})+\mathrm{B}_{2} \mathrm{O}_{3}(\mathrm{l}) \\
& \mathrm{B}_{2} \mathrm{O}_{3}(\mathrm{l}) \rightarrow \mathrm{B}_{2} \mathrm{O}_{3}(\mathrm{~g})
\end{aligned}
$$

where $\mathrm{Me}=\mathrm{Zr}$ or Hf.

For all samples, weight gains are observed at lower temperature with TGA (1013 K for ZS and $948 \mathrm{~K}$ for HS and HSY) as shown in figure 3. Thus, as already observed, a threshold in boria amount and thus in $\mathrm{B}_{2} \mathrm{O}_{3}(\mathrm{~g})$ has to be overstepped before the appearance of the LIF signal. At this temperature $(<1473 \mathrm{~K}), \mathrm{SiC}$ is not yet oxidised (figure 2$)^{3}$. Thus, the following steady rise in the LIF signal between steps (1) and (2) is attributed to the enhanced 
volatilization of $\mathrm{B}_{2} \mathrm{O}_{3}$, leading to an increased quantity of $\mathrm{BO}_{2}(\mathrm{~g})$. This is confirmed by the slower increase in weight gain as measured by TGA (figure 3).

An inversion of trend is observed at step (2): the LIF signal slowly decreases despite the continuous rise of sample heating, up to step (3), indicating that less $\mathrm{BO}_{2}(\mathrm{~g})$ is formed in this temperature range (Table 3). This striking observation is associated with the beginning of the passive oxidation of $\mathrm{SiC}$ through reaction 3. Therefore, the enrichment of the glassy phase with silica increases its stability (higher viscosity) compared to the previous boria glassy layer (reaction 4).

$$
\begin{aligned}
& \mathrm{SiC}+4 \mathrm{O}_{2} \rightarrow \mathrm{SiO}_{2}(\mathrm{~s} / \mathrm{l})+\mathrm{CO}_{2}(\mathrm{~g}) \\
& \mathrm{SiO}_{2}(\mathrm{l})+\mathrm{B}_{2} \mathrm{O}_{3}(\mathrm{l}) \rightarrow\left\{\mathrm{SiO}_{2}: \mathrm{B}_{2} \mathrm{O}_{3}\right\}(\mathrm{l})
\end{aligned}
$$

Several studies have already shown that a $\mathrm{B}_{2} \mathrm{O}_{3}$ concentration gradient is formed in the borosilicate glassy layer as preferential evaporation of $\mathrm{B}_{2} \mathrm{O}_{3}$ is observed at the surface ${ }^{27-29}$. This lower concentration, and thus the lower activity of $\mathrm{B}_{2} \mathrm{O}_{3}$ at the surface explains the LIF signal decrease ${ }^{11,23,29}$. Passive oxidation of SiC is also detected using TGA, but at a higher

\begin{tabular}{|c|c|c|c|}
\hline Sample & $\begin{array}{l}\text { Detection of LIF } \\
\text { signal }\left(T_{1}, \text { (1) }\right.\end{array}$ & Step (2) onset $\left(\mathrm{T}_{2}\right)$. & Step (3) onset $\left(\mathbf{T}_{3}\right)$ \\
\hline$\overline{Z S}$ & $1263 \mathrm{~K}$ & $1553 \mathrm{~K}$ & $1643 \mathrm{~K}$ \\
\hline HS & $1223 \mathrm{~K}$ & $1433 \mathrm{~K}$ & $1573 \mathrm{~K}$ \\
\hline HSY & $1223 \mathrm{~K}^{*}$ & $1523 \mathrm{~K}$ & $1588 \mathrm{~K}$ \\
\hline
\end{tabular}
temperature.

Table 3: Temperatures of the onset of the three key steps T1, T2 and T3. *extrapolated temperature.

Between steps (3) and (4) small bumps in the LIF signal, immediately followed by a decrease in the signal are observed. This is called the "dynamic phase" and can be explained by a power peak which makes the oxide layer less stable. Thus, the $\mathrm{B}_{2} \mathrm{O}_{3}$-rich glassy layer, where the activity of $\mathrm{B}_{2} \mathrm{O}_{3}$ is higher, is exposed and, therefore, the volatilization of $\mathrm{B}_{2} \mathrm{O}_{3}$ is favoured. The glassy layer is thinner and less protective against oxidation, so that the oxidation of the material underneath is favoured and, as a consequence, quickly reforms a 
stable borosilicate glassy layer, and the LIF signal decreases. The subsequent signal bumps have the same origin (power peak) and the same consequences. Between each bump, the average intensity of the LIF signal increases as the temperature is continuously increasing. Compared to TGA, between 1300 and $1673 \mathrm{~K}$, the weight gain increases strongly for HSY, and more smoothly for HS. ZS has a different TGA behaviour, especially at $1473 \mathrm{~K}$. Instead of a decrease in the mass gain slope, which is observed for HS and HSY, there is an increase in this slope. This indicates a continuous oxidation of the materials.

Finally, the high intensity LIF signal peak coupled with a dramatic drop in the laser transmission signal is observed in step (4). At that moment, the probe laser beam is strongly attenuated because of the formation of a dense smoke of oxide particles in the plume, and the LIF signal is no longer detected. This step is also triggered by a power peak, but at this high temperature, the volatilization of the glassy layer is very intense, and the active oxidation of $\mathrm{SiC}$ is also favoured via the Reaction 5.

$$
\mathrm{SiC}+\mathrm{O}_{2}(\mathrm{~g}) \rightarrow \mathrm{SiO}(\mathrm{g})+\mathrm{CO}(\mathrm{g})
$$

The drop in the transmission signal is linked to the catastrophic volatilization of the glassy layer leading to a high amount of $\mathrm{B}_{2} \mathrm{O}_{3}$ and $\mathrm{SiO}$ particles in the atmosphere just above the sample. However, at $1673 \mathrm{~K}$, the mass gain measured by TGA increases noticeably for all the compositions (figure 3), which confirms that the volatilization of the borosilicate glassy phase promotes the oxidation of the material underneath.

These general trends are observed for all compositions. However, some differences are noticeable, such as the temperatures (T1, T2 and T3) of the onset of the three steps (1) to (3), the LIF signals between steps (3) and (4) and the LIF and transmission signals at step (4). These differences are discussed in the next section. 


\section{Discussion}

\subsection{Formation of the boria glassy phase}

Considering Table 3, it can be noticed that the temperature at which the LIF signal is first detected $\left(T_{1}\right)$ is slightly higher for ZS than for HS and HSY. Interestingly, weight gain is detected at lower temperatures in the TGA signal (around $1113 \mathrm{~K}$ for ZS and around $948 \mathrm{~K}$ for HS and HSY) indicating that the LIF signal $\mathrm{BO}_{2}(\mathrm{~g})$ is detected once a boria glassy layer is formed at the surface of the sample (figure 3). The later apparition of the $\mathrm{B}_{2} \mathrm{O}_{3}$ boria glassy phase and thus of the $\mathrm{BO}_{2}(\mathrm{~g})$ detection for $\mathrm{ZS}$ samples is observed using both experiments. This can be explained considering the volatility diagrams of $\mathrm{ZrB}_{2}$ and $\mathrm{HfB}_{2}{ }^{30,31}$ and the diagrams of Ellingham (figure 4). It is clearly shown that oxidation of $\mathrm{HfB}_{2}$ is favoured at a lower temperature than for $\mathrm{ZrB}_{2}$.

\subsection{Formation of the borosilicate layer}

The temperature at which the LIF signal stops increasing $\left(\mathrm{T}_{2}\right)$ is higher for $\mathrm{ZS}$ and HSY than for HS ( $100 \mathrm{~K}$ in difference). This phenomenon is worth noting since $\mathrm{T}_{2}$ marks the moment when $\mathrm{SiO}_{2}(1)$ effectively integrates the boria network to form a borosilicate layer, making it more stable and less subject to volatilization. SEM micrographs of the three materials after oxidation are shown in figures 5 and 6 .

The oxidised samples all develop a classic 3-layer oxide scale above the bulk material, from

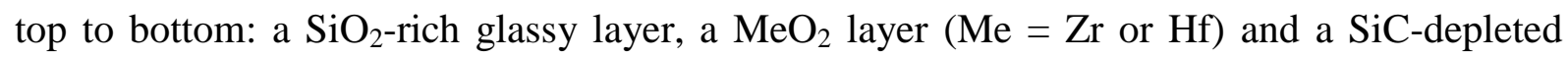
$\mathrm{MeB}_{2}$ layer. The SiC-depleted layer is formed by active oxidation of $\mathrm{SiC}$ (reaction 5), and the reaction product $\mathrm{SiO}(\mathrm{g})$ can diffuse towards the surface ${ }^{32}$. Once $\mathrm{SiO}(\mathrm{g})$ reaches the borosilicate layer, it can react with dissolved $\mathrm{O}_{2}(\mathrm{~g})$ to form $\mathrm{SiO}_{2}(\mathrm{l})$, thus participating in the replenishment of the glassy layer ${ }^{13,33,34}$ (reaction 6).

$\mathrm{SiO}(\mathrm{g})+1 / 2 \mathrm{O}_{2}(\mathrm{~g}) \rightarrow \mathrm{SiO}_{2}(\mathrm{l})$ 
From the SEM observations, it should be noted that the SiC-depleted layer has a very different relative thickness depending on the nature of the sample. HS sample develops a very thick SiC-depleted $\mathrm{HfB}_{2}$ layer $(\sim 500 \mu \mathrm{m}, 90 \%$ of the total oxide scale), HSY develops a thick SiC-depleted $\mathrm{HfB}_{2}$ layer $(\sim 250 \mu \mathrm{m}, 60 \%$ of the total oxide scale $)$ and $\mathrm{ZS}$ develops a comparatively thin $\mathrm{SiC}$-depleted $\mathrm{ZrB}_{2}$ layer $(\sim 60 \mu \mathrm{m}, 25 \% \text { of the total oxide scale })^{10,29,32}$, as reported in Table 4.

\begin{tabular}{cccc}
\hline & $\begin{array}{c}\text { SiC-depleted layer } \\
(\boldsymbol{\mu m})\end{array}$ & $\begin{array}{c}\text { Glassy phase layer } \\
(\boldsymbol{\mu m})\end{array}$ & $\begin{array}{c}\text { Total oxidised layer } \\
(\boldsymbol{\mu m})\end{array}$ \\
\hline ZS & 60 & 180 & 240 \\
HS & 500 & 55 & 555 \\
\hline HSY & 250 & 170 & 420 \\
\hline
\end{tabular}

Table 4: Thickness of each layer in the oxidised layers for all the tested compositions (average values from 10 measurements).

Moreover, $\mathrm{HS}$ develops a very thin $\mathrm{HfO}_{2}$ layer compared to the $\mathrm{SiC}$-depleted $\mathrm{HfB}_{2}$ layer or to other compositions. The composition of the glassy layer surface is directly dependent on the different reaction products that replenish it during the oxidation test. $\mathrm{B}_{2} \mathrm{O}_{3}(\mathrm{l})$ only comes from the oxidation of $\mathrm{HfB}_{2}$ whereas $\mathrm{SiO}_{2}(\mathrm{l})$ only comes from (directly or via active oxidation) the oxidation of SiC. Thus, the borosilicate layer developed by HS will likely be enriched in $\mathrm{SiO}_{2}(\mathrm{l})$ compared to HSY and ZS. This enrichment leads to an early stabilisation of the glassy layer, and that is why step (2) happens at a lower temperature for HS. For HSY, step (2) happens at $1523 \mathrm{~K}$, closer to the step (2) of ZS (1553 K). First, HSY develops a thinner SiCdepleted layer compared to HS: this means that the borosilicate layer is comparatively enriched in $\mathrm{B}_{2} \mathrm{O}_{3}$, which delays the stabilisation effect provided by $\mathrm{SiO}_{2}$. Secondly, the glassy phase is able to solubilise $\mathrm{Y}_{2} \mathrm{O}_{3}$ during its convection to the surface ${ }^{21,35,36,13}$. Thus, the dissolution of $\mathrm{Y}_{2} \mathrm{O}_{3}$ in the borosilicate glass decreases its viscosity and, therefore, its capability to act as an oxygen diffusion barrier, since a low viscosity favours the diffusion of oxygen through the borosilicate layer. To form a SiC-depleted layer, the oxygen partial 
pressure $\mathrm{P}_{\mathrm{O} 2}$ should be low enough to oxidise $\mathrm{SiC}$ without oxidising $\mathrm{HfB}_{2}{ }^{32,10,37}$. If the glassy layer is less protective towards oxygen diffusion, the formation of a SiC-depleted layer is hindered in favour of the oxidation of both $\mathrm{SiC}$ and $\mathrm{HfB}_{2}$. This explains why, when $\mathrm{Y}_{2} \mathrm{O}_{3}$ is added to a $\mathrm{HfB}_{2}-\mathrm{SiC}$ composition, the stabilisation provided by $\mathrm{SiO}_{2}(\mathrm{l})$ is triggered at a higher temperature. Then, comparing ZS and the two other compositions, ZS exhibits the thinnest SiC-depleted layer and the thickest glassy layer, indicating that the glassy layer formed at the top surface of ZS samples is $\mathrm{B}_{2} \mathrm{O}_{3}$-rich compared to the glassy phases developed by $\mathrm{HS}$ and HSY. Thus, the glassy layer of ZS is more permeable towards oxygen, thus promoting the oxidation of both $\mathrm{SiC}$ and $\mathrm{ZrB}_{2}$ (figure $5 \mathrm{a}$ and $\mathrm{b}$ ). Another aspect that should be taken into consideration is that, at the experiment temperature $(\mathrm{T}<1900 \mathrm{~K})$, tetragonal- $\mathrm{ZrO}_{2}$ is a better oxygen conductor than monoclinic- $\mathrm{HfO}_{2}{ }^{38,39}$. Thus, this point accentuates the fact that the active oxidation of $\mathrm{SiC}$ is not favoured in the $\mathrm{ZS}$ composition.

\subsection{The dynamic phase}

The beginning of step (3) always corresponds to a peak in the LIF signal (figure 2) and a strong increase in the weight gain (figure 3). In this temperature range $(>1573 \mathrm{~K})$ the volatilization of $\mathrm{B}_{2} \mathrm{O}_{3}$ becomes very intense ${ }^{20}$ and explains the constant increase in the average level of LIF signal observed in figure 2. However, in the present cases, the volatilization of boria is attenuated by the presence of silica in the glassy layer and the composition of the sample induces some differences in the LIF and transmission signals. For HSY, once the dynamic phase has begun, the average level of the LIF signal remains almost constant, despite the continuous increase in temperature. In parallel, the transmission slowly decreases from 1473 to $1823 \mathrm{~K}$. This means that there is a continuous formation of $\mathrm{B}_{2} \mathrm{O}_{3}$ droplets and, therefore, a steady volatilization of the borosilicate phase. But, the HSY material developed a very thick borosilicate layer containing a large amount of recrystallised $\mathrm{HfO}_{2}$ particles (figure $6 \mathrm{~b}$ ). The thickness of the glassy layer explains its resilience, i.e. its capacity 
to recover an average LIF signal level after the power peak. Moreover, Talmy et al. ${ }^{2}$ have shown that the presence of immiscible phases in a glassy layer could increase its viscosity and, therefore, limit the diffusion of oxygen. During its convection, the $\mathrm{B}_{2} \mathrm{O}_{3}$-rich glass is able to solubilise $\mathrm{Y}_{2} \mathrm{O}_{3}$ and $\mathrm{HfO}_{2}$. When reaching the surface, $\mathrm{B}_{2} \mathrm{O}_{3}$ preferentially evaporates, so that $\mathrm{Y}_{2} \mathrm{O}_{3}$ and $\mathrm{HfO}_{2}$ attain their saturation concentration and precipitate. Therefore, the continuous volatilization of $\mathrm{B}_{2} \mathrm{O}_{3}$ throughout the oxidation test favours the continuous precipitation of the solubilised components, which, in turn, increases the stability of the glassy layer.

For ZS, during the dynamic phase, the average level of the LIF signal increases after each peak (figure 2). For this sample, the stabilisation provided by $\mathrm{SiO}_{2}$ is less effective since the glassy layer is $\mathrm{B}_{2} \mathrm{O}_{3}$-rich, and the volatilization of $\mathrm{B}_{2} \mathrm{O}_{3}$ is, therefore, thermo-activated throughout the dynamic phase. The laser transmission signal also decreases steadily; consequently, there is a continuous formation of $\mathrm{B}_{2} \mathrm{O}_{3}$ droplets. Compared to HSY, the LIF signal takes more time to reach the low level after each signal peak $(\sim 180 \mathrm{~s}$ compared to $\sim 60 \mathrm{~s}$ for HSY). This means that a longer time is required for the sample to regenerate a glassy layer with a good stability. This is mostly due to the fact that the glassy layer of the oxidised ZS sample is $\mathrm{B}_{2} \mathrm{O}_{3}$-rich, which means that it is more subjected to volatilization, and that a larger quantity is required in order to get the same protection, due to the lower viscosity of $\mathrm{B}_{2} \mathrm{O}_{3}$-rich borosilicate glass. On the contrary, the glassy layer developed by HSY contains relatively more $\mathrm{SiO}_{2}$, so that it is more stable, and the material developed a thick SiC-depleted layer, which means that the replenishment of the layer is made with a $\mathrm{SiO}_{2}$-richer glass, explaining why the glassy layer more rapidly attains stability.

The LIF signal behaviour of HS during oxidation is similar to that of ZS. Each LIF signal peak is followed by an increase in the average LIF signal level. But, contrary to the other samples, the laser transmission signal was almost constant throughout the experiment. 
The LIF peaks are also very sharp. To explain these observations, it should be remembered that the borosilicate glass formed by $\mathrm{HS}$ is likely very $\mathrm{SiO}_{2}$-rich, since the $\mathrm{SiC}$-depleted zone is 9 times thicker than the $\mathrm{HfO}_{2}$ layer. The deficiency in $\mathrm{B}_{2} \mathrm{O}_{3}$ explains that there is no or not enough formation of $\mathrm{B}_{2} \mathrm{O}_{3}$ droplets and, therefore, the transmission level is unchanged. It can be noticed that the LIF signal peak at $2100 \mathrm{~s}(1783 \mathrm{~K})$ is accompanied by a short drop in the transmission level, thus meaning that, at this temperature, some $\mathrm{B}_{2} \mathrm{O}_{3}$ droplets are formed in a short time. As evidenced in figure 5, the borosilicate layer is likely thin and $\mathrm{SiO}_{2}$-rich during the test. Contrary to the HSY sample, where the height of LIF signal peaks was about a half of the average LIF signal level, the LIF signal peaks observed for HS are much more prominent, and can be ten times higher than the average LIF signal level. Due to the $\mathrm{B}_{2} \mathrm{O}_{3}$ deficiency and, therefore, the thinness of the HS borosilicate layer, this glassy phase is much more sensitive to a power peak. After the power peak, the borosilicate layer is even thinner, and this triggers the oxidation of the underlying $\mathrm{HfB}_{2}$, which will refill the borosilicate glass at the surface.

\subsection{Intense volatilization of $\mathrm{B}_{2} \mathrm{O}_{3}$}

Step (4) also illustrated some differences in the oxidation behaviour of the different materials. For the ZS sample, the final LIF signal peak was accompanied by a drastic drop in transmission. For the HS material, this step is characterised by a moderate LIF signal peak and a decrease in the transmission signal. And, finally, for HSY, there is a high intensity LIF signal peak, but there is only a small laser transmission decrease (from 0.7 to 0.6 ).

Regarding ZS sample, the LIF and transmission signals are associated with a catastrophic volatilization of the $\mathrm{B}_{2} \mathrm{O}_{3}$-rich borosilicate layer. This is confirmed by the final microstructure of the oxidised ZS sample (figure 5 a), where the glassy layer is very thin or non-existent. However, SEM micrographs of the surface of the oxidised ZS sample (figure 6 a and b) clearly show two features: the first is that, despite the thinness of the glassy layer, it still almost covers the whole surface of the sample, and the second is that the glassy layer is 
filled with recrystallized $\mathrm{ZrO}_{2}$ (small particles and large dendritic structures). The crystallites in the glassy layer constitute an indirect proof of the intense volatilization of $\mathrm{B}_{2} \mathrm{O}_{3}$. The fact that the borosilicate layer covers the entire surface reveals the low viscosity of this layer, probably due to its poverty in $\mathrm{SiO}_{2}$. The step (4) of HSY is also characterised by an intense LIF signal peak, but not a drastic transmission drop. As explained earlier, the thickness of the glassy layer developed by HSY allows the borosilicate glass to be more resilient towards the power peak. Even if the LIF signal of $\mathrm{BO}_{2}$ increases, there are not enough $\mathrm{B}_{2} \mathrm{O}_{3}$ droplets formed to drastically lower the laser transmission and, therefore, the volatilization cannot be qualified as catastrophic. This is confirmed by the SEM observations; the glassy layer is thick (figure $5 \mathrm{e}$ and $\mathrm{f}$ ) and covers the whole surface (figure $6 \mathrm{e}$ and $\mathrm{f}$ ). As in the case of $\mathrm{ZS}$, the overwhelming presence of crystallites and dendritic structures of $\mathrm{Y}_{2} \mathrm{O}_{3}$-doped $\mathrm{HfO}_{2}$ at the surface constitutes an evidence of the constant volatilization of $\mathrm{B}_{2} \mathrm{O}_{3}$ during the oxidation test. The case of HS is very different. As explained above, the step (4) of HS is not characterised by an intense LIF signal peak. But a closer examination of the transmission signal reveals that there is a very short but intense drop at $2400 \mathrm{~s}(1833 \mathrm{~K})$. SEM observations of the HS microstructure showed that the glassy layer was thin (figure $5 \mathrm{c}$ and $\mathrm{d}$ ) and did not cover the whole surface of the sample (figure $6 \mathrm{c}$ and d). The fact that there is simply not enough $\mathrm{B}_{2} \mathrm{O}_{3}$ in the remaining borosilicate layer to generate enough detectable $\mathrm{BO}_{2}$ can explain that there is no intense LIF signal at the end. The lack of $\mathrm{B}_{2} \mathrm{O}_{3}$ means that the viscosity of the borosilicate layer increases, thus, explaining that the glassy layer does not cover the entire surface of the sample.

\section{Conclusion}

The oxidation behaviours of $\mathrm{ZrB}_{2}-\mathrm{SiC}, \mathrm{HfB}_{2}-\mathrm{SiC}$ and $\mathrm{HfB}_{2}-\mathrm{SiC}-\mathrm{Y}_{2} \mathrm{O}_{3}$ materials were studied using the real-time LIF detection of evaporated $\mathrm{BO}_{2}(\mathrm{~g})$, above the samples heated up to $1873 \mathrm{~K}$ in a dry air atmosphere. For each composition, the starting point of the influence of 
$\mathrm{SiC}$ on the stability of the glassy layer and the catastrophic volatilization of the glassy layer can be precisely determined. Moreover, the influence of the composition on the oxidation behaviour can be understood and described using this technique.

In order to form a stable glassy layer, the $\mathrm{B}_{2} \mathrm{O}_{3} / \mathrm{SiO}_{2}$ ratio must be finely tuned. If this ratio is too high, as it seems to be the case for $\mathrm{ZS}$, then the glassy layer is not stabilised enough by $\mathrm{SiO}_{2}$, and the glassy layer will completely volatilize at $\sim 1873 \mathrm{~K}$. If it is too low, for instance for the HS material, then there is not enough "matter" to create a thick glassy layer that will completely cover the surface of the sample. On the contrary, a good compromise is achieved for HSY: this sample is not only able to generate a thick borosilicate layer, but the preferential volatilization of $\mathrm{B}_{2} \mathrm{O}_{3}$ will trigger the precipitation of $\mathrm{HfO}_{2}$ particles, that will in turn increase the stability of the glassy layer in the considered temperature range.

As it was already shown, LIF is a promising method, which can be quantitative, to study in situ, and thus continuously, the oxidation behaviour of UHTC. Moreover, the influence of the composition and its ability to form a protective layer can be studied and determined. Thus, the interest of the LIF technique in the detection of thermal oxidation is clearly confirmed. 


\section{Acknowledgements}

The authors would like to thank M. Bejet and T. Schmid (ONERA) for modifying the oxidation chamber and, finally, Dr P. Beauchêne and Dr. R. Valle (ONERA) for their kind and efficient assistance.

\section{Data availability}

The raw/processed data required to reproduce these findings cannot be shared at this time due to legal or ethical reasons.

\section{Authors' contributions}

V. Guérineau is the $\mathrm{PhD}$ student who has manufactured the samples, tested them, performed the post-test analyses and written the article. N. Dorval and G. Vilmart are the specialists of the LIF technique and have helped to modify the bench and prepare the

experiments. V. Guérineau, N. Dorval and G. Vilmart have performed all the LIF experiments. A. Julian-Jankowiak is the $\mathrm{PhD}$ supervisor, she has helped to modify the bench, to analyse the results and to write the paper.

All the authors have read and approved the final version of this article. 


\section{Bibliography}

1. Opila, E., Levine, S. \& Lorincz, J. Oxidation of $\mathrm{ZrB}_{2^{-}}$and $\mathrm{HfB}_{2}$-based ultra-high temperature ceramics: effect of Ta additions. J. Mater. Sci. 39, 5969-5977 (2004).

2. Talmy, I. G., Zaykoski, J., Opeka, M. M. \& Dallek, S. Oxidation of $\mathrm{ZrB}_{2}$ ceramics modified with $\mathrm{SiC}$ and group IV-VI transition metal diborides. Electrochem. Soc. Proc. 12, 144-158 (2001).

3. Williams, P. A., Sakidja, R., Perepezko, J. H. \& Ritt, P. Oxidation of $\mathrm{ZrB}_{2}-\mathrm{SiC}$ ultra-high temperature composites over a wide range of SiC content. J. Eur. Ceram. Soc. 14, 38753883 (2012).

4. Zhang, P., Hu, P., Zhang, X., Han, J. \& Meng, S. Processing and characterization of $\mathrm{ZrB}_{2}-$ $\mathrm{SiC}_{\mathrm{W}}$ ultra-high temperature ceramics. J. Alloys Compd. 472, 358-362 (2009).

5. Zhang, S. C., Fahrenholtz, W. G. \& Hilmas, G. E. Oxidation of $\mathrm{ZrB}_{2}$ and $\mathrm{ZrB}_{2}-\mathrm{SiC}$ ceramics with tungsten additions. High Temperature Corrosion and Materials Chemistry, Electrochem. Soc. Trans. 16, 137-145 (2008).

6. Carney, C. M., Mogilvesky, P. \& Parthasarathy, T. A. Oxidation behavior of zirconium diboride silicon carbide produced by the spark plasma sintering method. J. Am. Ceram. Soc. 92, 2046-2052 (2009).

7. Fahrenholtz, W. G. \& Hilmas, G. E. Oxidation of ultra-high temperature transition metal diboride ceramics. Int. Mater. Rev. 57, 61-72 (2012).

8. Monteverde, F. The thermal stability in air of hot-pressed diboride matrix composites for uses at ultra-high temperatures. Corros. Sci. 47, 2020-2033 (2005).

9. Carney, C. M. Oxidation resistance of hafnium diboride-silicon carbide from 1400 to $2000{ }^{\circ}$ C. J. Mater. Sci. 44, 5673-5681 (2009).

10. Shugart, K. \& Opila, E. SiC depletion in $\mathrm{ZrB}_{2}-30$ vol\% SiC at ultrahigh temperatures. $J$. Am. Ceram. Soc. 98, 1673-1683 (2015).

11. Shugart, K., Jennings, W. \& Opila, E. Initial stages of $\mathrm{ZrB}_{2}-30$ vol\% SiC oxidation at $1500^{\circ}$ C. J. Am. Ceram. Soc. 97, 1645-1651 (2014).

12. $\mathrm{Hu}, \mathrm{P}$. , Guolin, W. \& Wang, Z. Oxidation mechanism and resistance of $\mathrm{ZrB}_{2}-\mathrm{SiC}$ composites. Corros. Sci. 51, 2724-2732 (2009).

13. Guérineau, V. \& Julian-Jankowiak, A. Oxidation mechanisms under water vapour conditions of $\mathrm{ZrB}_{2}-\mathrm{SiC}$ and $\mathrm{HfB}_{2}-\mathrm{SiC}$ based materials up to $2400^{\circ} \mathrm{C}$. J. Eur. Ceram. Soc. 38, 421-432 (2018).

14. Opila, E. J. \& Halbig, M. C. Oxidation of $\mathrm{ZrB}_{2}$-SiC. Ceram. Eng. Sci. Proc. 22, 221-228 (2001).

15. Nguyen, Q. N., Opila, E. J. \& Robinson, R. C. Oxidation of ultrahigh temperature ceramics in water vapor. J. Electrochem. Soc. 151, B558-B562 (2004).

16. Alfano, D., Scatteia, L., Monteverde, F., Bêche, E. \& Balat-Pichelin, M. Microstructural characterization of $\mathrm{ZrB}_{2}-\mathrm{SiC}$ based UHTC tested in the MESOX plasma facility. J. Eur. Ceram. Soc. 30, 2345-2355 (2010).

17. Marschall, J., Pejaković, D.A., Fahrenholtz, W.G., Hilmas, G.E., Panerai, F. \& Chazot, O. Temperature jump phenomenon during plasmatron testing of $\mathrm{ZrB}_{2}-\mathrm{SiC}$ ultrahightemperature ceramics. J. Thermophys. Heat Transf. 26, 559-572 (2012).

18. Carney, C., Paul, A.,Venugopal, S., Parthasarathy, T., Binner, J., Katz, A. \& Brown, P. Qualitative analysis of hafnium diboride based ultra high temperature ceramics under oxyacetylene torch testing at temperatures above $2100^{\circ}$ C. J. Eur. Ceram. Soc. 34, 10451051 (2014). 
19. Paul, A., Venugopal, S., Binner, J., Vaidhyanathan, B., Heaton, A.C.J. \& Brown, P. UHTC-carbon fibre composites: preparation, oxyacetylene torch testing and characterisation. J. Eur. Ceram. Soc. 33, 423-432 (2013).

20. Tripp, W. C. \& Graham, H. C. Thermogravimetric study of the oxidation of $\mathrm{ZrB}_{2}$ in the temperature range of $800^{\circ}$ to $1500^{\circ}$ C. J. Electrochem. Soc. 118, 1195-1199 (1971).

21. Opeka, M. M., Talmy, I. G. \& Zaykoski, J. A. Oxidation-based materials selection for $2000^{\circ} \mathrm{C}+$ hypersonic aerosurfaces: Theoretical considerations and historical experience. J. Mater. Sci. 39, 5887-5904 (2004).

22. Li, H., Yao, X.Y., Zhang, Y.L., Li, K.Z., Guo, L.J., \& Liu, L. Effect of heat flux on ablation behaviour and mechanism of $\mathrm{C} / \mathrm{C}-\mathrm{ZrB}_{2}-\mathrm{SiC}$ composite under oxyacetylene torch flame. Corros. Sci. 74, 265-270 (2013).

23. Sevast'yanov, V. G., Simonenko, E.P., Gordeev, A.N., Simonenko, N.P., Kolesnikov, A.F., Papynov, E.K., Shichalin, O.O., Avramenko, V.A. \& Kuznetsov, N.T. Behavior of a sample of the ceramic material $\mathrm{HfB}_{2}-\mathrm{SiC}(45 \mathrm{vol} \%)$ in the flow of dissociated air and the analysis of the emission spectrum of the boundary layer above its surface. Russ. J. Inorg. Chem. 60, 1360-1373 (2015).

24. Playez, M., Fletcher, D.G., Marschall, J., Fahrenholtz, W.G., Hilmas, G.E. \& Zhu, S. Optical emission spectroscopy during plasmatron testing of $\mathrm{ZrB}_{2}-\mathrm{SiC}$ ultrahightemperature ceramic composites. J. Thermophys. Heat Transf. 23, 279-285 (2009).

25. Guérineau, V., Julian-Jankowiak, A., Vilmart, G. \& Dorval, N. In situ study of the oxidation of $\mathrm{ZrB}_{2}$ and $\mathrm{ZrB}_{2}-\mathrm{SiC}$ materials by monitoring the LIF signal of $\mathrm{BO}_{2}$ radicals. Corros. Sci. 148, 31-38 (2019).

26. Johns, J. W. C. The absorption spectrum of $\mathrm{BO}_{2}$. Can. J. Phys. 39, 1738-1768 (1961).

27. Karlsdottir, S. N. \& Halloran, J. W. Oxidation of $\mathrm{ZrB}_{2}-\mathrm{SiC}$ : influence of SiC content on solid and liquid oxide phase formation. J. Am. Ceram. Soc. 92, 481-486 (2009).

28. Karlsdottir, S. N., Halloran, J. W. \& Henderson, C. E. Convection patterns in liquid oxide films on $\mathrm{ZrB}_{2}-\mathrm{SiC}$ composites oxidized at a high temperature. J. Am. Ceram. Soc. 90, 2863-2867 (2007).

29. Karlsdottir, S. N. \& Halloran, J. W. Formation of oxide scales on zirconium diboridesilicon carbide composites during oxidation: relation of subscale recession to liquid oxide flow. J. Am. Ceram. Soc. 91, 3652-3658 (2008).

30. Fahrenholtz, W. G. The $\mathrm{ZrB}_{2}$ volatility diagram. J. Am. Ceram. Soc. 88, 3509-3512 (2005).

31. Li, H., Zhang, L., Zeng, Q. \& Cheng, L. Thermodynamic calculation of $\mathrm{HfB}_{2}$ volatility diagram. J. Phase Equilibria Diffus. 32, 422-427 (2011).

32. Fahrenholtz, W. G. Thermodynamic analysis of $\mathrm{ZrB}_{2}-\mathrm{SiC}$ oxidation: formation of a SiCdepleted region. J. Am. Ceram. Soc. 90, 143-148 (2007).

33. Parthasarathy, T. A., Rapp, R. A., Opeka, M. \& Cinibulk, M. K. Modeling oxidation kinetics of SiC-containing refractory diborides. J. Am. Ceram. Soc. 95, 338-349 (2012).

34. Simonenko, E. P., Sevast'yanov, D. V., Simonenko, N. P., Sevast'yanov, V. G. \& Kuznetsov, N. T. Promising ultra-high-temperature ceramic materials for aerospace applications. Russ. J. Inorg. Chem. 58, 1669-1693 (2013).

35. Fahrenholtz, W. G., Hilmas, G. E., Talmy, I. G. \& Zaykoski, J. A. Refractory diborides of zirconium and hafnium. J. Am. Ceram. Soc. 90, 1347-1364 (2007).

36. Tian, Z., Zhu, Y. \& Huang, W. Effect of yttrium oxide on the viscosity and crystallization of borosilicate glass at high temperature. Adv. Mater. Res. 750-752, 974-977 (2013).

37. Opila, E. J., Smialek, J. L., Robinson, R. C., Fox, D. S. \& Jacobson, N. S. SiC recession caused by $\mathrm{SiO}_{2}$ scale volatility under combustion conditions: II, thermodynamics and gaseous-diffusion model. J. Am. Ceram. Soc. 82, 1826-1834 (1999). 
38. Trubelja, M. F. \& Stubican, V. S. Ionic conductivity of the fluorite-type hafnia- $\mathrm{RE}_{2} \mathrm{O}_{3}$ solid solutions. J. Am. Ceram. Soc. 74, 2489-2494 (1991).

39. Corman, G. S. \& Stubican, V. S. Phase equilibria and ionic conductivity in the system $\mathrm{ZrO}_{2}-\mathrm{Yb}_{2} \mathrm{O}_{3}-\mathrm{Y}_{2} \mathrm{O}_{3}$. J. Am. Ceram. Soc. 68, 174-181 (1985). 


\section{Figures captions}

Figure 1: (a) a schematic view of the chamber and (b) LIF set-up.

Figure 2: Surface temperature (left axis), normalised LIF and transmission signals (right axis) vs. time of (a) $\mathrm{ZrB}_{2}-\mathrm{SiC}$, (b) $\mathrm{HfB}_{2}-\mathrm{SiC}$ and (c) $\mathrm{HfB}_{2}-\mathrm{SiC}-\mathrm{Y}_{2} \mathrm{O}_{3}$ materials during an oxidation test in dry air under 0.1 MPa. Key steps (numbered 1 to 4 ) are described in the text.

Figure 3: Mass variation vs. time of HS, ZS and HSY. Temperature ramp is $2 \mathrm{~K} / \mathrm{min}$. The TGA is performed under a $50 \mathrm{ml} / \mathrm{min}$ flux of air. Inset: a zoom on TGA signals between 800 and $1200 \mathrm{~K}$.

Figure 4: Diagram of Ellingham for $\mathrm{Si}, \mathrm{Zr}$ and Hf elements.

Figure 5: SEM micrographs of polished cross-sections of oxidised samples: (a, b) ZS, (c, d) HS and (e, f) HSY. The different layers are (1) borosilicate glass, (2) $\mathrm{MeO}_{2}\left(\mathrm{Me}=\mathrm{Zr}\right.$ or $\mathrm{Hf}$ ), (3) SiC-depleted $\mathrm{MeB}_{2}$ and (4) bulk material.

Figure 6: SEM micrographs of the surfaces of oxidised samples: (a, b) ZS, (c, d) HS and (e, f) HSY materials. In grey, the borosilicate layer and in white, zirconia or hafnia inclusions and dendritic structures. (f) Recrystallised $\mathrm{HfO}_{2}$ is omnipresent (in white) as dendrites and crystallites in the borosilicate layer (grey).

Tables captions:

Table 1: Grade, purity and particle size of starting powders.

Table 2: Sintering conditions and open porosity of the studied UHTC materials.

Table 3: Temperatures of the onset of the three key steps T1, T2 and T3. *extrapolated temperature.

Table 4: Thickness of each layer in the oxidised layers for all the tested compositions (average values from 10 measurements). 
(a)

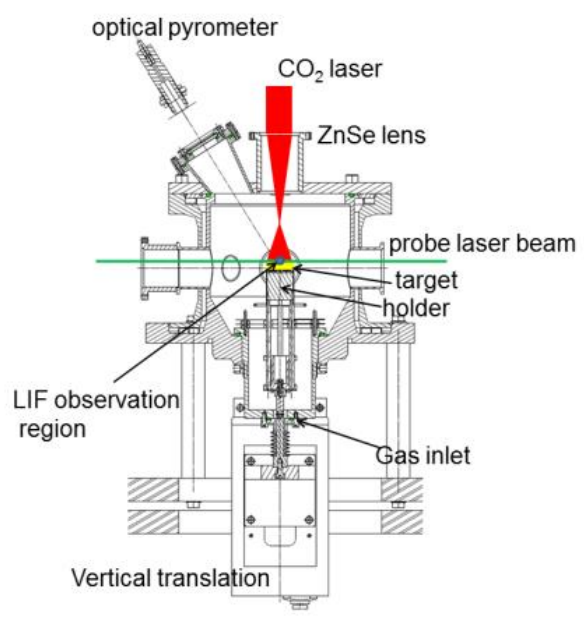

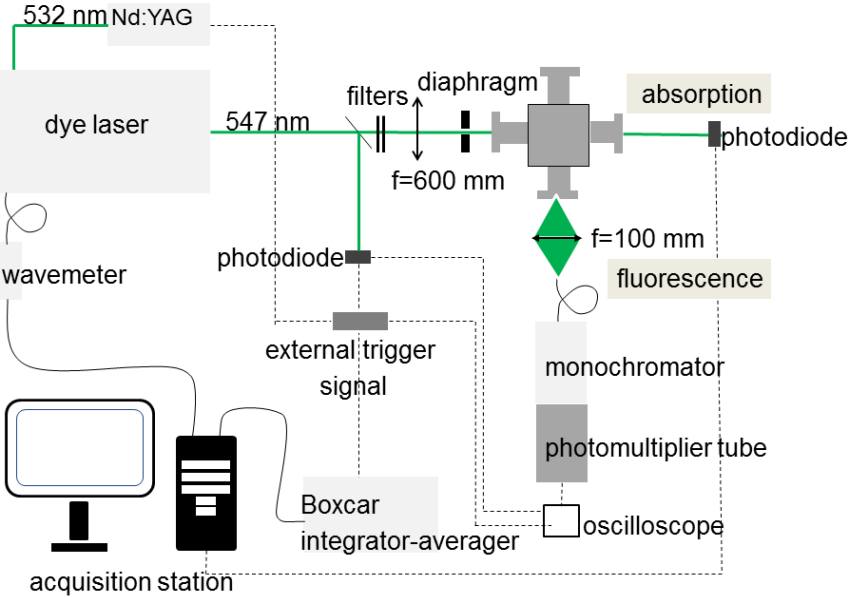

Figure 1: (a) a schematic view of the chamber and (b) LIF set-up. 
(a)



(b) 2073

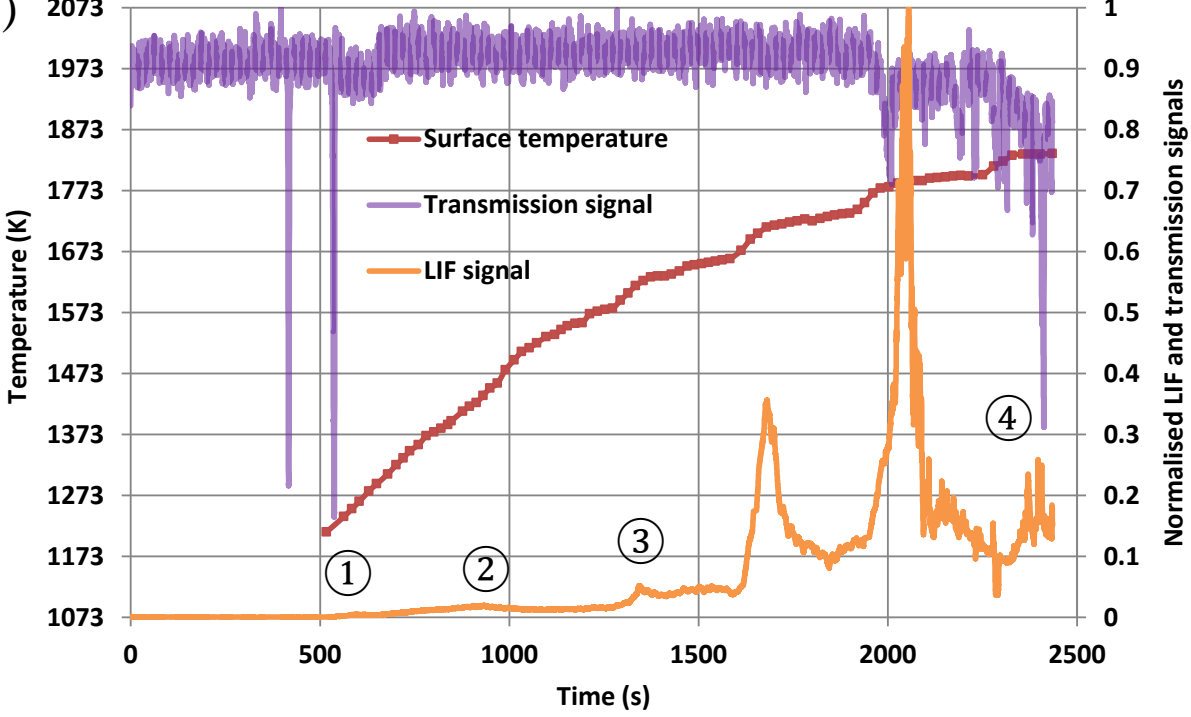

(c)



Figure 2: Surface temperature (left axis), normalised LIF and transmission signals (right axis) vs. time of (a) $\mathrm{ZrB}_{2}$-SiC, (b) $\mathrm{HfB}_{2}$-SiC and (c) $\mathrm{HfB}_{2}-\mathrm{SiC}-\mathrm{Y}_{2} \mathrm{O}_{3}$ materials during an oxidation test in dry air under 0.1 MPa. Key steps (numbered 1 to 4) are described in the text. 


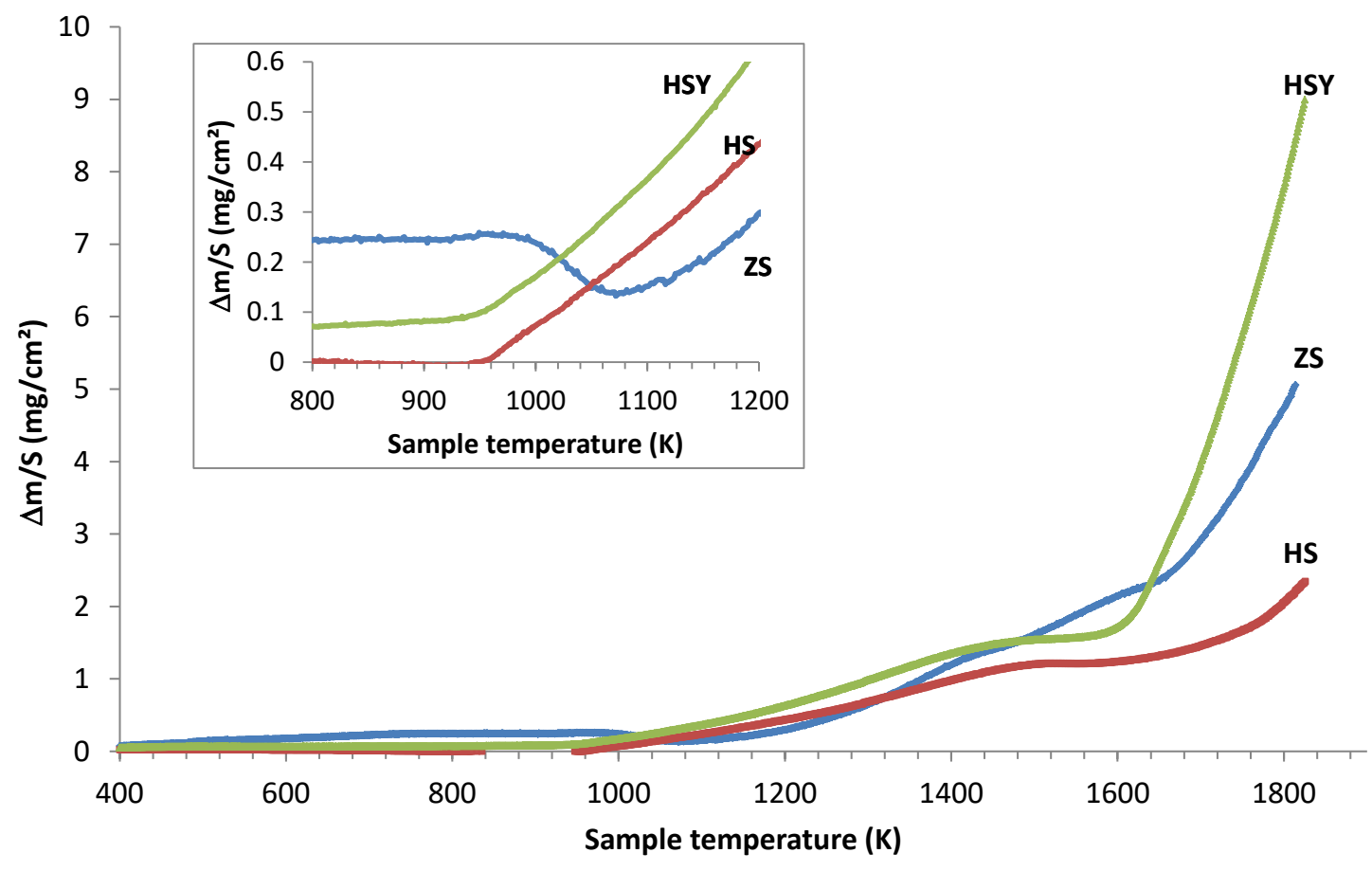

Figure 3: Mass variation vs. time of HS, ZS and HSY. Temperature ramp is $2 \mathrm{~K} / \mathrm{min}$. The TGA is performed under a $50 \mathrm{ml} / \mathrm{min}$ flux of air. Inset: a zoom on TGA signals between 800 and $1200 \mathrm{~K}$.

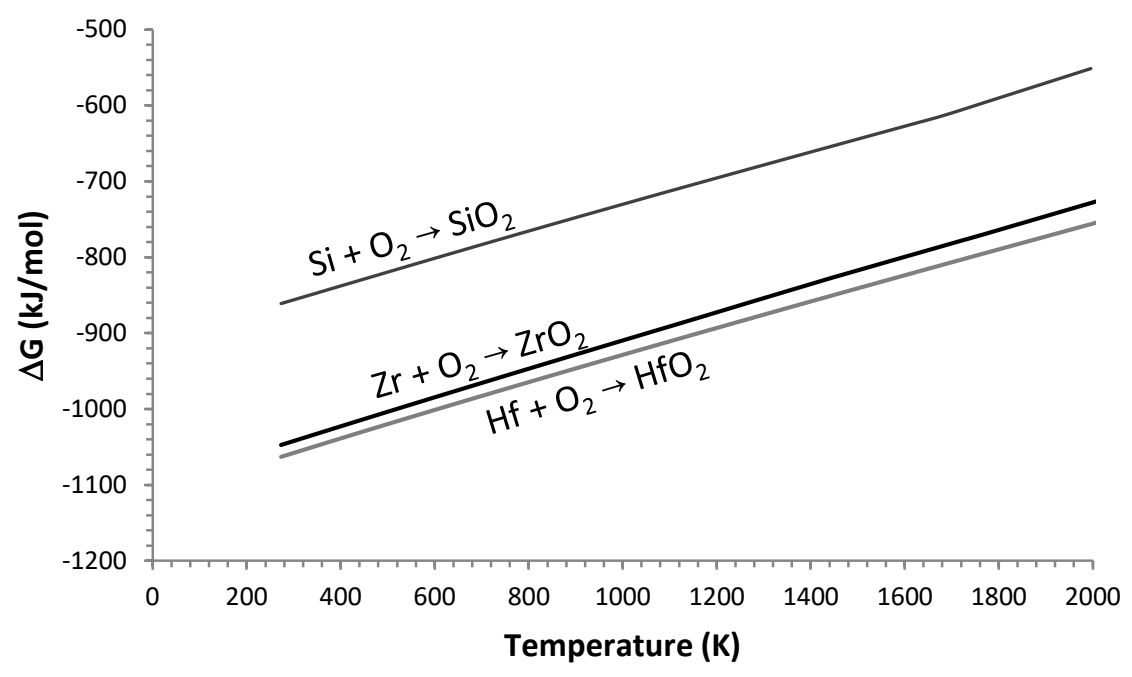

Figure 4: Diagram of Ellingham for $\mathrm{Si}, \mathrm{Zr}$ and $\mathrm{Hf}$ elements. 

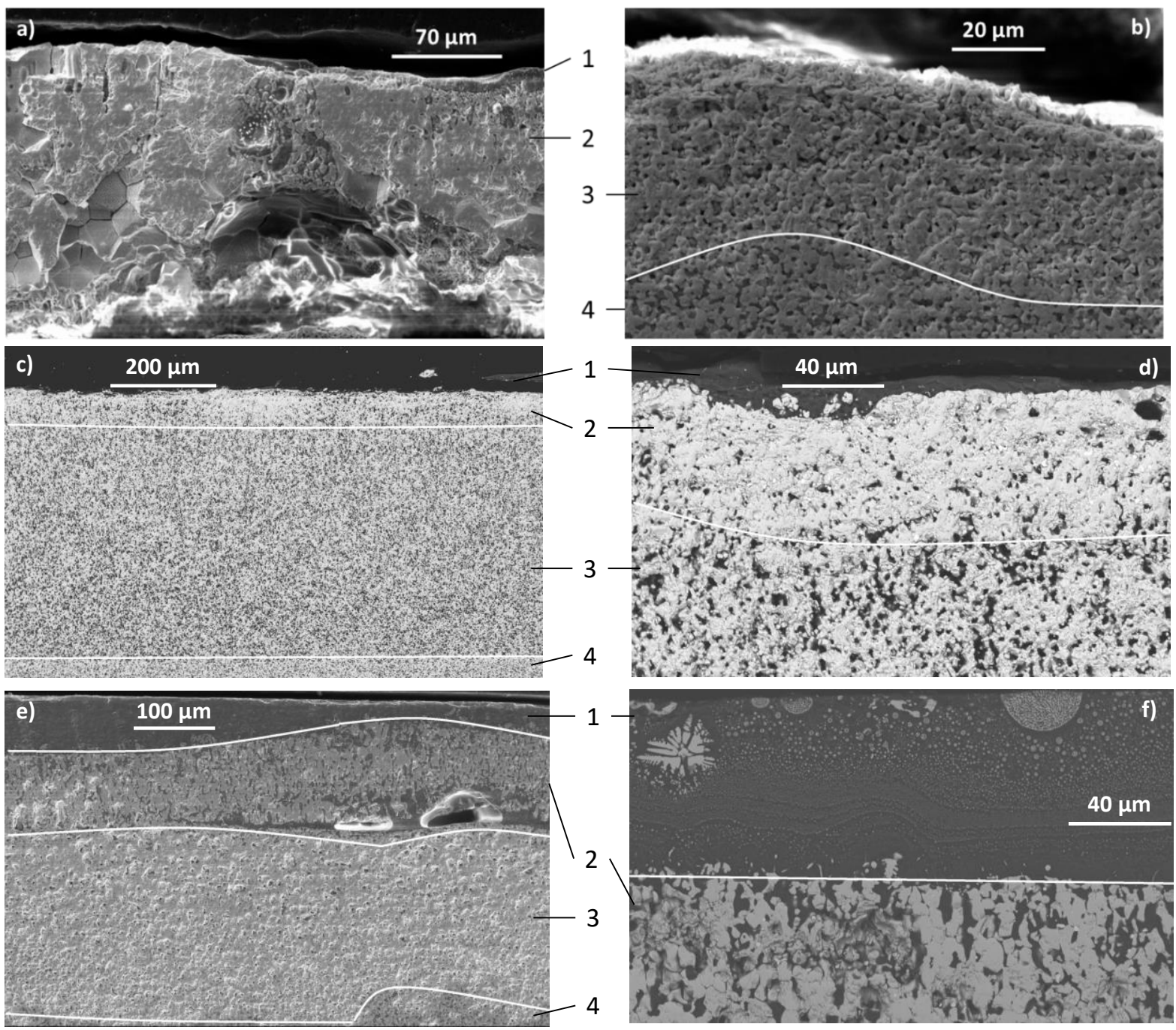

Figure 5: SEM micrographs of polished cross-sections of oxidised samples: (a, b) ZS, (c, d) HS and (e, f) HSY. The different layers are (1) borosilicate glass, (2) $\mathrm{MeO}_{2}(\mathrm{Me}=\mathrm{Zr}$ or $\mathrm{Hf})$, (3) SiC-depleted $\mathrm{MeB}_{2}$ and (4) bulk material. 

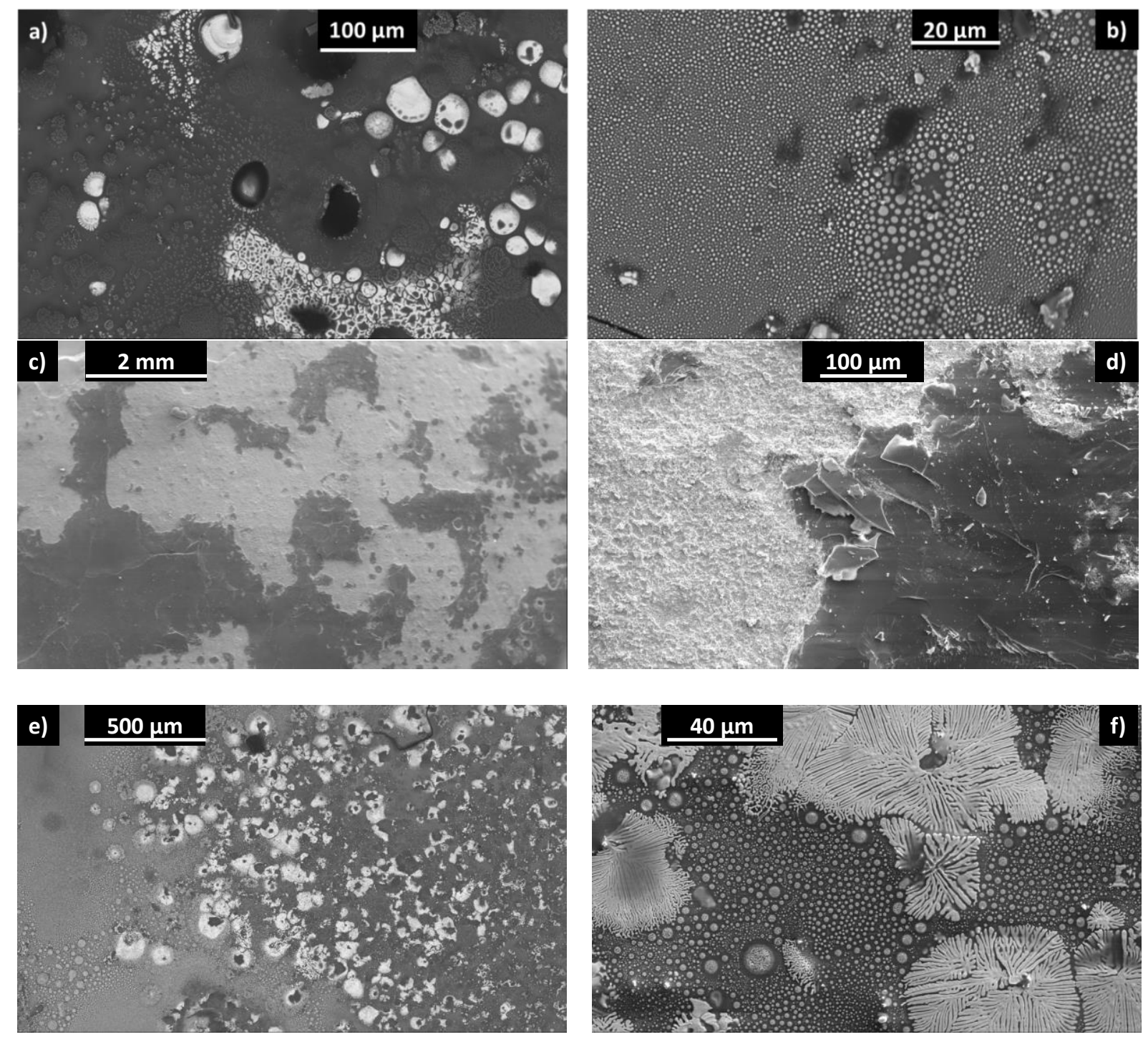

Figure 6: SEM micrographs of the surfaces of oxidised samples: (a, b) ZS, (c, d) HS and (e, f) HSY materials. In grey, the borosilicate layer and in white, zirconia or hafnia inclusions and dendritic structures. (f) Recrystallised $\mathrm{HfO}_{2}$ is omnipresent (in white) as dendrites and crystallites in the borosilicate layer (grey). 